\title{
Gluten-Free Rice Breading Using Composited Rice Flour and Pre-Germinated Brown Rice Flour for Health Benefits
}

\author{
Warunee KUPKANCHANAKUL ${ }^{1}$, Tomoko YAMAGUCHI ${ }^{2}$ and Onanong NAIVIKUL ${ }^{1,3, *}$ \\ ${ }^{1}$ Department of Food Science and Technology, Faculty of Agro-Industry, Kasetsart University, \\ Bangkok 10900, Thailand \\ ${ }^{2}$ Department of Life Science, Faculty of Education, Niigata University, Niigata City 950-2181, Japan \\ ${ }^{3}$ Associate Fellows, Academy of Science, Office of the Royal Society, Bangkok 10300, Thailand
}

\begin{abstract}
Summary Gluten-free rice breading (RB) is generally prepared by shredding of glutenfree rice bread. It is an alternative product for Celiac patients, who are gluten allergic. The aim of this research was to formulate gluten-free rice bread formula by using composited rice flour (RF) and pre-germinated brown rice flour (PGBRF) from two Thai rice cultivars, Pathum-Thani1 (15\% amylose) and Phitsanulok2 (27\% amylose) at the ratio of 1:1, by considering the structural properties of bread, health benefit of breading, and the properties of breading as coating material of fried frozen croquette $(\mathrm{C}-)$ and compared to those of samples prepared from wheat flour. Increasing PGBRF from $0 \%$ to $50 \%$ in gluten-free rice bread formula increased the puffed cell wall of air cell in gluten-free rice bread. Antioxidative activity of RB containing 50\% PGBRF (RB-50\%) was 4 and 9 times higher than RB without PGBRF $(\mathrm{RB}-0 \%)$ and wheat breading (WB), respectively. WB contained $356,289 \mathrm{mg} / \mathrm{kg}$ of gluten, while RB contained less than $2 \mathrm{mg} / \mathrm{kg}$ of gluten, which could be labeled "gluten-free". When compared all breading samples as coating material of $\mathrm{C}-$, oil absorption of $\mathrm{C}-\mathrm{RB}-50 \%$ (14.32\%) was 3 times lower than that of WB (44.36\%). Therefore, the RB-50\% had health benefits for consumers who are suffered from Celiac disease and also other health-conscious consumers considering the higher antioxidative properties and lower oil uptake than the consumption of WB.
\end{abstract}

Key Words pre-germinated brown rice, rice flour, gluten-free, breading

Breading (or breadcrumb or breader) is a flour-based breadcrumb or cracker meal that plays a major ingredient to coat over moistened or battered food products and create the unique characteristics. Generally, breading is made from wheat-based bread that is shredded and dried (1). However, the number of Celiac patients, who are wheat gluten allergic, has been increasingly reported at a rapid rate around the world (2-4). Many researchers suggested rice flour as gluten-free flour for bread making, but the gluten-free rice bread still exhibited some poor bread characteristics consisting of dense structure, hard texture, and quick retrogradation (5-7). It could be resulted a difficult flake-shredding and hard texture after frying of gluten-free rice breading. Therefore, the textural properties of gluten-free rice bread should be improved by modifying of rice components, particularly starch and protein.

Germination process has been widely reported to induce chemical changes of rice due to a complex biochemical process of starch, protein and other components being considerably activated, particularly during rice paddy growth at $0.5-7 \mathrm{~mm}$ of embryonic growth length (EGL), which is called pre-germination process $(8,9)$. Pre-germinated brown rice flour (PGBRF) from 24-48 h of germination, which were substituted in the

\footnotetext{
*To whom correspondence should be addressed.

E-mail: fagionn@ku.ac.th
}

composited wheat-rice bread formula, were reported to reduce hardness of bread after baking and to reduce staling rate after storage (10). In addition, the significant increasing total phenol content of waxy RD6 rice cultivar from $413.24 \mu \mathrm{mol}$ gallic acid eq./100 $\mathrm{g} \mathrm{dw}$ to $579.59 \mu \mathrm{mol}$ gallic acid eq./100 g dw were found after $96 \mathrm{~h}$ of paddy germination, which could be further applied as healthy food ingredients to obtain a higher antioxidative activity of rice-based products (11).

However, the effects of PGBRF substitution in glutenfree rice bread/breading formula on their structural and antioxidative properties are not well understood. Therefore, the objectives of this study were to investigate the effect of PGBRF substitution on the structural, antioxidative properties, and oil absorption of rice breading (RB) compared to those of wheat breading (WB) before and after applying as coating material of fried frozen croquette.

\section{Materials and Methods \\ Materials}

Two matured paddy Thai rice (Oryza sativa L.) cultivars-Pathum-Thani1 (PTT1; low amylose rice, 15\% amylose); and Phitsanulok2 (PNL2; high amylose rice, $27 \%$ amylose)—were used after 2 mo of dormancy and then stored at $-18^{\circ} \mathrm{C}$. Commercial wheat flour (WF; White Swan Bread Flour, United Flour Mill Public Co., Ltd., Thailand) and all ingredients of breading formula 
were obtained from a local market.

Preparation of composited rice flour (RF) and pre-germinated brown rice flour (PGBRF)

Rice paddy of PTT1 and PNL2 cultivars were dehusked, polished, dry-milled, and sieved through a 100mesh sieve to obtain dry-milled white rice flour of PTT1 (RF-PTT1) and dry-milled white rice flour of PNL2 (RFPNL2). RF-PTT1 and RF-PNL2 were composited at the ratio of $1: 1$ to obtain the composited rice flour (RF).

Pre-germinated paddy (PGP) of two Thai rice cultivars were prepared as described in our previous work (8). The total pre-germination time of PTT1 and PNL2 cultivars were 34 and $52 \mathrm{~h}$, respectively. PGP samples were dehusked, dry-milled, and sieved through a 100mesh sieve to obtain dry-milled pre-germinated brown rice flour of PTT1 (PGBRF-PTT1) and dry-milled pregerminated brown rice flour of PNL2 (PGBRF-PNL2). PGBRF-PTT1 and PGBRF-PNL2 were composited at the ratio of $1: 1$ to obtain the composited pre-germinated brown rice flour (PGBRF).

Preparation of bread, breading and fried frozen croquette samples

Rice bread samples were prepared by using mixture of RF and PGBRF at the ratio of 100:0, 75:25, and 50:50 before shredding to obtain rice breading containing PGBRF at $0 \%$ (RB-0\%), 25\% (RB-25\%), and 50\% (RB$50 \%$ ), respectively. Dried ingredients of bread formula consisting of flour (100\% baker), sugar $(2 \%)$, baking powder $(2 \%)$, and salt $(1 \%)$ were mixed by hand. The mixture of dried ingredients was added with an activated yeast suspension, which was a mixture of instant dried yeast (3\%) and water $(160 \%$ for dry matter of all RF samples and $80 \%$ for dry matter of WF) with a continue mixing by an automatic home bakery machine (KitchenAid) using mixed paddle for $1 \mathrm{~min}$ at $100 \mathrm{rpm}$ and then a rice bran oil with 8,000 ppm oryzanol (3\%) was added with a continue mixing at $200 \mathrm{rpm} 4 \mathrm{~min}$ for rice batter and $20 \mathrm{~min}$ for wheat dough. The mixture of all ingredients was fermented at $35^{\circ} \mathrm{C}$ with $85 \% \mathrm{RH}$ for $45 \mathrm{~min}$ before baked at $185^{\circ} \mathrm{C}$ with $1 \mathrm{~L}$ of steamed water for $25 \mathrm{~min}$. After that, the bread samples were cooled and dipped in liquid nitrogen before shredded breading samples. The moisture content of breading sample was adjusted to $29 \pm 2 \%$ for semi-dry breading using a hot air oven $\left(35^{\circ} \mathrm{C}\right.$ for $\left.30 \mathrm{~min}\right)$.

Fried frozen croquette coated by $\mathrm{RB}(\mathrm{C}-\mathrm{RB})$ and fried frozen croquette coated by WB $(\mathrm{C}-\mathrm{WB})$ samples were prepared by coating their breading samples on round mashed potato $(8 \mathrm{~g}$, diameter $=3.8 \mathrm{~cm}$ and thickness $=0.5 \mathrm{~cm}$ ), dipping in liquid nitrogen, and stored at $-18^{\circ} \mathrm{C}$ for a week before deep-frying at $180^{\circ} \mathrm{C}$ for $5 \mathrm{~min}$. Analysis of bread, breading and fried frozen croquette samples

Characteristic of air cell (at $100 \times$ ) and its cell wall (at $500 \times$ ) in bread samples were observed using scanning electron microscope (SEM: Tabletop Microscope; TM3030Plus, Hitachi, Japan).

After shredded breading samples, the bulk density of breading was determined according to the method described previously (15). The particle size distribution
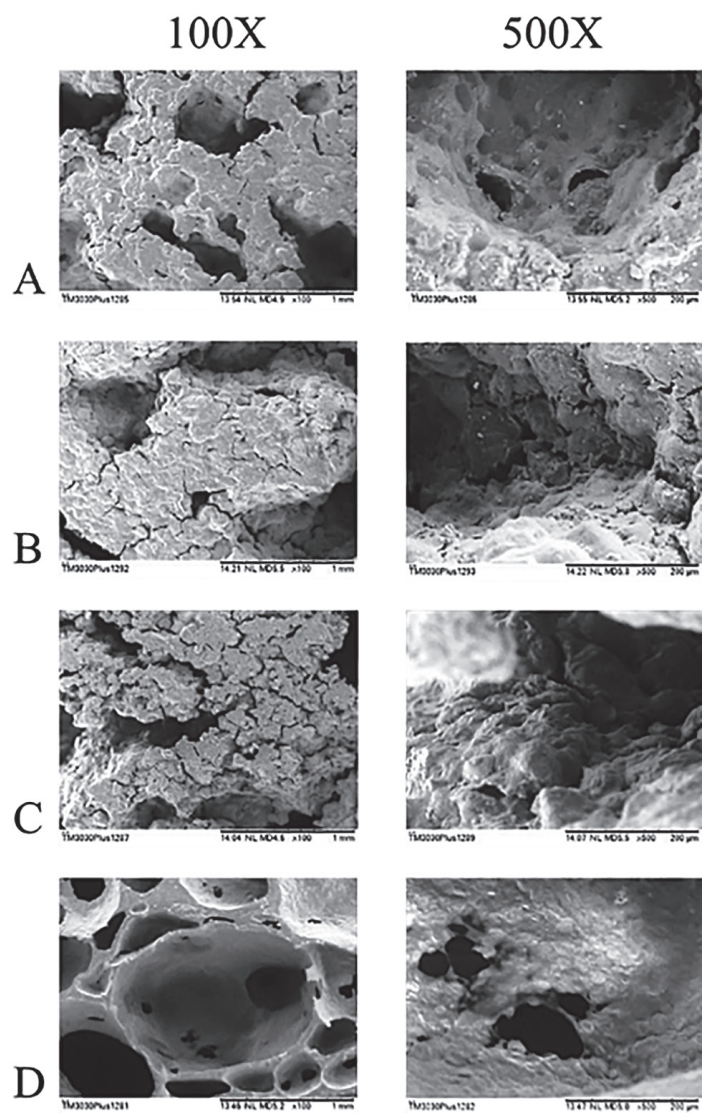

Fig. 1. Morphological properties of air cell (at $100 \times$, left) and its cell wall (at $500 \times$, right) in rice bread samples varying in substitution percentage of pre-germinated brown rice flour (PGBRF) at $0 \%(\mathrm{~A}), 25 \%(\mathrm{~B})$, and $50 \%$ (C) compared to that of wheat bread (D) observed by scanning electron microscope (SEM).

(\%) of breading was also determined according to the method described previously (15) with slight modification. Briefly, the particle size distribution of breading was classified into three proportion groups of breading sizes, i.e., coarse breading (larger than $850 \mu \mathrm{m}$ ), medium breading (between $250 \mu \mathrm{m}$ and $850 \mu \mathrm{m}$ ), and fine breading (smaller than $250 \mu \mathrm{m}$ ) by using sieve no. 20 mesh $(850 \mu \mathrm{m})$ and sieve no. 60 mesh $(250 \mu \mathrm{m})$. The pick-up capacity of breading was determined the weight of adhered breading, which coated on round mashed potato. It was calculated as the percent of pickup capacity based on weight of adhered breading per weight of cylinder mashed potato. Tocopherol derivatives in breading samples were determined using a reverse phase high performance liquid chromatography (RP-HPLC) as described previously (16). Total phenol content (TPC) of breading samples were determined, following a modified Folin-Ciocalteu reagent method as described previously (17) and calculated using Gallic acid in ethanol as standard. Radical-scavenging activity (RSA) of breading sample was determined by following a modified DPPH method and calculated using Trolox as standard (16). In addition, gluten content of breading samples were measured by determining the gliadin content using a monoclonal R5-antibody-based on sand- 
wich enzyme-linked immunosorbent assay (ELISA), wheat/gluten (gliadin) ELISA Kit II (Morinaga Institute of Biological Science, Inc.; Yokohama-Shi, Japan) according to the procedure of assay.

In order to apply the breading samples as coating material of croquette product, the appearances of frozen croquette samples before and after frying process were observed and recorded as photographs using a compact camera (Nikon Coolpix S9100, Nikon, Japan). Color values of fried frozen croquette samples were measured using a Mini scan XE (model 45/O-L by Hunter Association Laboratory, United States) according to the method described previously (15). Oil absorption of fried frozen croquette samples were determined according to the method described previously (18). Fried frozen croquette samples were drained to remove the oil by leaving them on a metal grid for $10 \mathrm{~min}$, and then weighed (A). Fried croquette samples were then wrapped with oil absorbent towel, which was weighed (B), for $1 \mathrm{~h}$ to absorb the oil. After that, the cooking paper with absorbed oil was weighed (C). The oil absorption was calculated using the following equation;

Oil absorption $=\left(\frac{(\mathrm{C}-\mathrm{B})}{\mathrm{A}}\right) \times 100$

After removing absorbed oil from fried frozen croquette samples, the breading part was separated from croquette samples, and then ground with a blender. Furthermore, the oil in ground fried breading was continually extracted with a modified Soxtec apparatus of Approved Method 30-20 with petroleum ether (a range of boiling point on $\left.35-60^{\circ} \mathrm{C}\right)(19)$.

Experimental design and statistical analysis

Complete randomize design (CRD) was applied to determine all properties of samples. All sample measurements were expressed as a mean \pm standard deviation (SD). Data were analyzed using the SPSS 11.0 software (SPSS Inc., Chicago, IL, USA) for one-way ANOVA. The Tukey's multiple comparison test was used for detection the statistically significant difference among the investigated groups of samples with a 95\% confidence interval.

\section{Results and Discussion}

\section{Bread characteristics}

SEM micrographs show the differences in morphological properties of all rice bread samples and wheat bread (Fig. 1). All bread samples contained continuous air cells with solid cell wall. Rice bread (Fig. 1A-C) contained smaller air cells with thicker cell wall than those of wheat bread (Fig. 1D). In particular, PGBRF substitution in rice bread formula affected cell wall characteristic. The cell wall of rice bread containing 25\% PGBRF (Fig. 1B) and rice bread containing 50\% PGBRF (Fig. $1 C)$ showed the increasing of roughness with puff surface compared to rice bread without PGBRF (Fig. 1A). The morphology structures of wheat bread continually contained air cell with thin cell wall. The cell wall in wheat bread samples had rough surface with small puff surface. The increasing of puff cell wall RB with PGBRF was probably due to the partial degradation of rice starch molecules (9). This could be related to a lower paste viscosity during rice batter proofing and also in the early stages of baking, which might have facilitated batter expansion. Additionally, the preserved batter elasticity and the increased paste stability during baking insured the structural integrity of the bread to be cell wall of air cell. In addition, the reduction of disulfidelinked macromolecular protein during pre-germination could also enhance the forming of rice bread structure (8). The existence of disulfide-linked protein polymer was surrounding starch granules (20). Disulfide-linked macromolecular proteins are natively present in rice endosperm or formed and strengthened during cooking, work as a barrier and restrict the heat-induced swelling of rice starch and thus the rheological and cooking properties of rice resulting in a barrier to form the structure of rice bread $(13,14,21)$.

Breading properties

Subsequently, breading samples were prepared by shredding of bread samples. The physical properties as bulk density, particle size distribution, and pick-up capacity of rice breading (RB) samples were evaluated and compared to those of wheat breading (WB). They are shown in Table 1. Bulk density of WB was found to be $226.9 \mathrm{~kg} / \mathrm{m}^{3}$, which was significantly $(p<0.05)$ lower than those of all RB samples at the range of $439.2-$ $459.1 \mathrm{~kg} / \mathrm{m}^{3}$. Normally, bulk density of breading is known to range from $200 \mathrm{~kg} / \mathrm{m}^{3}$ to $600 \mathrm{~kg} / \mathrm{m}^{3}$ as more to less porosity (22). Our results showed that bulk densities of all breading samples were within normal range of bulk density. In addition, coarse breading with larger particles than $850 \mu \mathrm{m}$ showed a main proportion of particle size for all breading samples, which ranged from $77.6 \%$ to $84.4 \%$. Fine breading with smaller particles than $250 \mu \mathrm{m}$ was hardly found ranging from $2.8 \%$ to $3.3 \%$. Pick-up capacity of WB was found to be $45.00 \%$ which was not significantly $(p \geq 0.05)$ different from those of RB (45.63-46.38\%). When compared among RB samples, the substitution of PGBRF between $0 \%$ and $50 \%$ in rice bread formula did not affect bulk density and pick-up capacity of shredded RB, but it significantly affected increasing proportion of coarse breading and decreasing proportion of medium breading, particularly at $50 \%$ PGBRF substitution. This led to the change in proportions of particle size of RB-50\% samples, which were close to the proportions of particle size in WB.

Antioxidative properties of all rice breading $(\mathrm{RB})$ and wheat breading (WB) are shown in Table 2. The radicalscavenging activity (RSA) and total phenol content of $\mathrm{RB}$ was significantly higher than that of WB. Moreover, the RB-25\% and RB-50\% showed significant increase of both antioxidative properties. The highest RSA and total phenol content were found in RB-50\% at $110.28 \mu \mathrm{mol}$ Trolox eq./100 g dw and $155.30 \mu \mathrm{mol}$ Gallic acid eq./100 g dw, respectively. 25\% and 50\% PGBRF substitution significantly increased the total phenol contents of $\mathrm{RB}$ at 5 times and 7 times, respectively. The contents of four tocopherol derivatives of RB were significantly increased when PGBRF substitutions in formula, especially alpha- and gamma-tocopherol. These results confirmed the antioxidative potential of $\mathrm{RF}$ particularly 
Table 1. Bulk density, proportions of particle size, pick-up capacity of rice breading (RB) samples varying in substitution percentage of pre-germinated brown rice flour (PGBRF) at $0 \%$ (RB-0\%), 25\% (RB-25\%), and 50\% (RB-50\%) and compared to that of wheat breading (WB).

\begin{tabular}{|c|c|c|c|c|c|}
\hline \multirow{2}{*}{$\begin{array}{l}\text { Breading } \\
\text { samples }\end{array}$} & \multirow{2}{*}{$\begin{array}{l}\text { Bulk density }{ }^{1} \\
\quad\left(\mathrm{~kg} / \mathrm{m}^{3}\right)\end{array}$} & \multicolumn{3}{|c|}{ Proportions of particle size ${ }^{1}(\%)$} & \multirow{2}{*}{ Pick-up ${ }^{1}(\%)^{\mathrm{n}}$} \\
\hline & & $<250 \mu \mathrm{m}$ & $250-850 \mu \mathrm{m}$ & $>850 \mu \mathrm{m}$ & \\
\hline RB-0\% & $439.2 \pm 14.1^{\mathrm{a}}$ & $3.1 \pm 0.2^{\mathrm{b}}$ & $19.3 \pm 0.6^{\mathrm{a}}$ & $77.6 \pm 0.8^{b}$ & $45.63 \pm 3.47$ \\
\hline RB- $25 \%$ & $447.6 \pm 8.1^{\mathrm{a}}$ & $3.3 \pm 0.3^{\mathrm{a}}$ & $15.0 \pm 0.9^{b}$ & $81.7 \pm 1.8^{\mathrm{a}}$ & $46.13 \pm 3.27$ \\
\hline RB- $50 \%$ & $459.1 \pm 18.3^{\mathrm{a}}$ & $3.1 \pm 0.2^{b}$ & $13.0 \pm 1.1^{\mathrm{c}}$ & $83.9 \pm 1.5^{\mathrm{a}}$ & $46.38 \pm 2.93$ \\
\hline WB & $226.9 \pm 4.9^{b}$ & $2.8 \pm 0.4^{\mathrm{c}}$ & $12.8 \pm 0.7^{\mathrm{c}}$ & $84.4 \pm 1.4^{\mathrm{a}}$ & $45.00 \pm 4.97$ \\
\hline
\end{tabular}

${ }^{1}$ Results are expressed as mean \pm SD $(n=6)$. Means with different lowercase letters in the same column are significantly different $(p<0.05)$. ${ }^{\text {ns }}$ refers to not significantly different $(p \geq 0.05)$.

Table 2. Antioxidative properties of rice breading (RB) samples varying in substitution percentage of pre-germinated brown rice flour (PGBRF) at 0\% (RB-0\%), 25\% (RB-25\%), and 50\% (RB-50\%) and compared to that of wheat breading (WB).

\begin{tabular}{|c|c|c|c|c|c|c|}
\hline \multirow{2}{*}{$\begin{array}{l}\text { Breading } \\
\text { sample }\end{array}$} & \multirow{2}{*}{$\begin{array}{l}\text { Total Phenol Content } \\
(\mu \mathrm{mol} \text { gallic acid } \\
\text { eq./100 g dw })\end{array}$} & \multicolumn{4}{|c|}{ Content of tocopherol derivatives ${ }^{1}(\mu \mathrm{g} / \mathrm{g} \mathrm{dw})$} & \multirow{2}{*}{$\begin{array}{l}\text { Radical-scavenging } \\
\text { activity }^{1}(\mu \mathrm{mol} \text { Trolox } \\
\text { eq. } / 100 \mathrm{~g} \mathrm{dw})\end{array}$} \\
\hline & & Alpha & Beta & Gamma & Delta & \\
\hline RB- $0 \%$ & $17.99 \pm 0.67^{\mathrm{c}}$ & $0.07 \pm 0.01^{\mathrm{c}}$ & $0.02 \pm 0.00^{c}$ & $1.78 \pm 0.09^{\mathrm{b}}$ & $0.00 \pm 0.00^{\mathrm{b}}$ & $27.67=$ \\
\hline RB- $25 \%$ & $90.53 \pm 0.63^{b}$ & $0.76 \pm 0.02^{b}$ & $0.07 \pm 0.01^{\mathrm{b}}$ & $1.88 \pm 0.10^{\mathrm{b}}$ & $0.07 \pm 0.01^{\mathrm{a}}$ & $69.56 \pm 0.61^{b}$ \\
\hline $\mathrm{RB}-50 \%$ & $155.30 \pm 0.76^{\mathrm{a}}$ & $1.39 \pm 0.03^{\mathrm{a}}$ & $0.11 \pm 0.01^{\mathrm{a}}$ & $2.57 \pm 0.13^{\mathrm{a}}$ & $0.09 \pm 0.01^{\mathrm{a}}$ & $110.28 \pm 0.29^{\mathrm{a}}$ \\
\hline WB & $12.40 \pm 0.53^{\mathrm{d}}$ & $0.01 \pm 0.00^{\mathrm{d}}$ & $0.02 \pm 0.00^{\mathrm{c}}$ & $0.89 \pm 0.16^{\mathrm{c}}$ & $0.00 \pm 0.00^{b}$ & $12.23 \pm 0.23^{\mathrm{d}}$ \\
\hline
\end{tabular}

${ }^{1}$ Results are expressed as mean \pm SD $(n=3)$. Means with different lowercase letters in the same column are significantly different $(p<0.05)$.

PGBRF to be the functional ingredients as rancidity prevention for dried food as breading and fried food as fried croquette and also prevent many oxidative stress-linked diseases, e.g., cancer, immunodeficiency, and inflammatory response.

In addition, the gluten contents of all RB samples were less than $2 \mathrm{mg} / \mathrm{kg}$, while that of WB was $356,289 \mathrm{mg} /$ $\mathrm{kg}$ (Table 3). It indicated that all RB samples can be claimed to be gluten-free RB followed by the regulation of the International Codex Alimentarius Commission standard, in which, the gluten content of gluten-free products have to be less than $20 \mathrm{mg} / \mathrm{kg}$ in total based on the food ready for consumption (23). Therefore, all RB samples are the alternative gluten-free products for Celiac patients, who are gluten allergic.

Fried frozen croquette characteristics

In order to apply the breading samples as coating material of croquette product, the coating characteristics of all frozen croquette coated by $\mathrm{RB}(\mathrm{C}-\mathrm{RB})$ samples were similar to that of frozen croquette coated by WB $(\mathrm{C}-\mathrm{WB})$ before and after frying processes as shown in Fig. 2. It was due to the fact that all breading samples were semi-dry breading, which contained suitable moisture around 30\% for food coating. All C-RB samples and C-WB were fully covered and adhered to the surface of croquette substrate with less falling out after frozen process and frying process. In addition, the PGBRF substitu-
Table 3. Gluten content of rice breading (RB) samples varying in substitution percentage of pre-germinated brown rice flour (PGBRF) at $0 \%$ (RB- $0 \%$ ), 25\% (RB$25 \%$ ), and $50 \%(\mathrm{RB}-50 \%)$ and compared to that of wheat breading $(\mathrm{WB})$.

\begin{tabular}{cc}
\hline Breading sample & Gluten content $(\mathrm{mg} / \mathrm{kg})$ \\
\hline RB-0\% & $<2$ \\
RB-25\% & $<2$ \\
RB-50\% & $<2$ \\
WB & 356,289 \\
\hline
\end{tabular}

tion in rice bread formula led to the increase in yellowness and redness of $\mathrm{C}-\mathrm{RB}$ and the decrease in lightness, which was closely similar to that of C-WB (Table 4). The increasing yellowness of RB after PGBRF substitution was probably due to the PGBRF containing sugar, which was the product of partial degradation of starch during pre-germination (9).

Furthermore, oil absorption and oil content of fried frozen croquette samples are shown in Table 5. The oil absorption at $44.36 \%$ and oil content at $28.63 \%$ of C-WB were significantly $(p<0.05)$ higher than those of all C-RB samples at the ranges of 14.32-22.98\% for oil absorption and 10.58-14.56\% for oil content. 


\section{Before frying After frying}

A
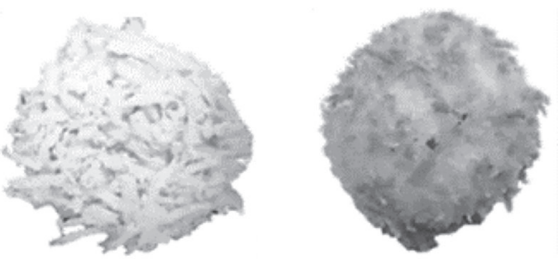

B
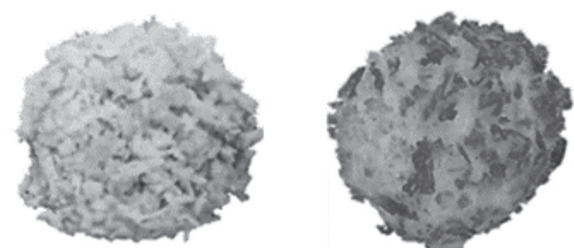

$\mathrm{C}$
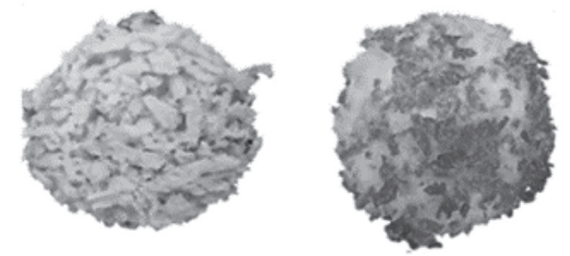

D

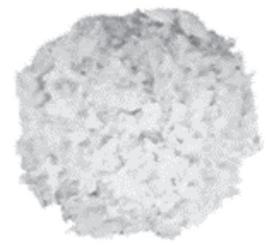

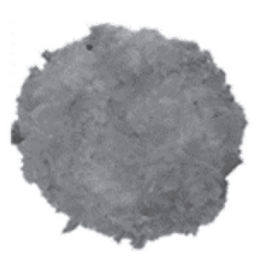

Fig. 2. Appearance of frozen croquette coated by RB (C-RB) samples varying in substitution percentage of pre-germinated brown rice flour (PGBRF) at $0 \%$ (C-RB0\%; A), 25\% (C-RB-25\%; B), and 50\% (C-RB-50\%; C) and compared to frozen croquette coated by WB $(\mathrm{C}-\mathrm{WB}$; D) before (left) and after (right) frying.

The 25-50\% substitutions of PGBRF in RB formula significantly decreased both oil absorption and oil content of their C-RB- $0 \%$. It clearly indicated that using of RB samples, particularly RB-50\%, as coating material of fried food is more health benefit than using of $\mathrm{WB}$, because of lower oil absorption.

In conclusion, the increasing percent substitution with PGBRF up to $50 \%$ in rice bread formula led to improve the structural properties of rice bread and physical properties of $\mathrm{RB}$, and it had also significant effects on increasing antioxidative properties of $\mathrm{RB}$. The highest antioxidative activity of RB-50\% was 4 times higher than the RB without PGBRF and 9 times higher than the WB. The gluten contents of all RB samples were less than $2 \mathrm{mg} / \mathrm{kg}$, which were not considered an allergen to Celiac patients and could be labeled "glutenfree product". Furthermore, RB-50\% was also shown a good coating material of croquette product to provide the desired golden color after frying process. In addition, C-RB-50\% also provided the health benefits as 3 times lower oil absorption than C-WB. Therefore, the RB-50\% was not only a gluten-free RB for Celiac patients, but it was also a better breading for health-conscious consumers considering the higher antioxidative properties to
Table 4. Color of fried frozen croquette coated by RB (C-RB) samples varying in substitution percentage of pre-germinated brown rice flour (PGBRF) at $0 \%(\mathrm{C}-\mathrm{RB}-$ 0\%), 25\% (C-RB-25\%), and 50\% (C-RB-50\%) and compared to that of fried frozen croquette coated by $\mathrm{WB}$ (C-WB).

\begin{tabular}{lrrr}
\hline \multirow{2}{*}{$\begin{array}{c}\text { Croquette } \\
\text { sample }\end{array}$} & \multicolumn{3}{c}{ Color parameter $^{1}$} \\
\cline { 2 - 4 } & $\mathrm{L}^{*}$ & $(+) \mathrm{a}^{*}$ & $(+) \mathrm{b}^{*}$ \\
\hline $\mathrm{C}-\mathrm{RB}-0 \%$ & $60.54 \pm 2.04^{\mathrm{a}}$ & $6.57 \pm 0.32^{\mathrm{b}}$ & $22.61 \pm 1.29^{\mathrm{d}}$ \\
$\mathrm{C}-\mathrm{RB}-25 \%$ & $54.93 \pm 1.97^{\mathrm{b}}$ & $13.92 \pm 0.24^{\mathrm{a}}$ & $25.98 \pm 0.96^{\mathrm{c}}$ \\
$\mathrm{C}-\mathrm{RB}-50 \%$ & $49.92 \pm 1.57^{\mathrm{c}}$ & $13.95 \pm 0.71^{\mathrm{a}}$ & $32.75 \pm 1.08^{\mathrm{a}}$ \\
$\mathrm{C}-\mathrm{WB}$ & $51.76 \pm 1.98^{\mathrm{c}}$ & $13.86 \pm 0.96^{\mathrm{a}}$ & $30.02 \pm 1.54^{\mathrm{b}}$
\end{tabular}

${ }^{1}$ Results are expressed as mean \pm SD $(n=10)$. Means with different lowercase letters in the same column are significantly different $(p<0.05)$. $\mathrm{L}^{*}=$ Lightness, $(+) \mathrm{a}^{*}=$ redness, and $(+) \mathrm{b}^{*}=$ yellowness.

Table 5. Oil absorption and oil content of fried frozen croquette coated by RB (C-RB) samples varying in substitution percentage of pre-germinated brown rice flour (PGBRF) at 0\% (C-RB-0\%), 25\% (C-RB-25\%), and 50\% (C-RB-50\%) and compared to that of fried frozen croquette coated by WB (C-WB).

\begin{tabular}{lcc}
\hline $\begin{array}{c}\text { Croquette } \\
\text { sample }\end{array}$ & Oil absorption (\%) & Oil content (\%) \\
\hline C-RB-0\% & $22.98 \pm 0.19^{\mathrm{b}}$ & $14.56 \pm 0.98^{\mathrm{b}}$ \\
C-RB-25\% & $16.94 \pm 0.14^{\mathrm{c}}$ & $11.80 \pm 0.70^{\mathrm{c}}$ \\
C-RB-50\% & $14.32 \pm 0.11^{\mathrm{d}}$ & $10.58 \pm 0.77^{\mathrm{c}}$ \\
C-WB & $44.36 \pm 0.52^{\mathrm{a}}$ & $28.63 \pm 0.38^{\mathrm{a}}$ \\
\hline
\end{tabular}

${ }^{1}$ Results are expressed as mean \pm SD $(n=9)$. Means with different lowercase letters in the same column are significantly different $(p<0.05)$.

prevent some disease, which related to oxidative stress. In addition, the RB-50\% was a better coating material of croquette product as lower oil absorption than WB.

\section{Disclosure of State of COI}

The authors declare that they have no conflicts of interest.

\section{Acknowledgements}

This research was financially supported by the Royal Golden Jubilee Ph.D. program scholarship (contract No. PHD/0037/2552), which was jointly funded by the Thailand Research Fund (TRF) and Kasetsart University, Bangkok, Thailand.

\section{Human and Animal Rights}

This article does not contain any studies with human or animal subjects. 


\section{REFERENCES}

1) Suderman DR, Cunningham FE. 1983. Batter and Breading. AVI Publishing Company, Westport, Connecticut, USA.

2) Poddar U, Thapa BR, Nain CK, Prasad A, Singh K. 2002. Celiac disease in India: are they true cases of celiac disease? J Pediatr Gastroenterol Nutr 35: 508-512.

3) Makharia GK, Mulder CJ, Goh KL, Ahuja V, Bai JC, Catassi C, Green PH, Gupta SD, Lundin KE, Ramakrishna BS, Rawat R, Sharma H, Sood A, Watanabe C, Gibson PR. 2014. Issues associated with the emergence of coeliac disease in the Asia-Pacific region: a working party report of the World Gastroenterology Organization and the Asian Pacific Association of Gastroenterology. J Gastroenterol Hepatol 29(4): 666-677.

4) Al-Bawardy B, Codipilly DC, Rubio-Tapia A, Bruining DH, Hansel SL, Murray JA. 2017. Celiac disease: a clinical review. Abdom Radiol 42: 351-360.

5) Deis RC. 1997. Functional ingredients from rice. Food Prod Des 6: 45-46.

6) Gujral HS, Rosell CM. 2004. Improvement of the breadmaking quality of rice flour by glucose oxidase. Food Research International 37: 75-81.

7) Moron B, Cebolla A, Manyani H, Alvarez-Maqueda M, Megias M, Thomas M del C, Lopez MC, Sousa C. 2008. Sensitive detection of cereal fractions that are toxic to celiac disease patients by using monoclonal antibodies to a main immunogenic wheat peptide. Am J Clin Nutr 87: 405-414.

8) Kupkanchanakul W, Kadowaki M, Kubota M, Naivikul O. 2018. Effect of pre-germination varying stages of embryonic growth length on chemical composition and protein profile of Thai rice (Oryza sativa L.). Agriculture and Natural Resources 52: 59-65.

9) Kupkanchanakul W, Thongngam M, Shi YC, Naivikul O. 2018. Role of amylolytic activities during pre-germination on rice kernel morphology and physicochemical properties of isolated starch. Cereal Chem 95: 543-554.

10) Charoenthaikij P, Jangchud K, Jangchud A, Prinyawiwatkul W, Kyoon K, King JM. 2010. Physicochemical properties and consumer acceptance of wheat-germinated brown rice bread during storage time. J Food Sci 75: 333-339.

11) Moongngarm A, Saetung N. 2010. Comparison of chemical compositions and bioactive compounds of germinated rough rice and brown rice. Journal of Food
Chemistry 122: 782-788.

12) Nishita KD, Roberts RL, Bean MM. 1976. Development of a yeast-leavened rice-bread formula. Cereal Chem 53(5): 626-635.

13) Renzetti S, Arendt EK. 2009. Effect of protease treatment on the baking quality of brown rice bread: from textural and rheological properties to biochemistry and microstructure. J Cereal Sci 50: 22-28.

14) Yano H. 2010. Improvements in the bread-making quality of gluten-free rice batter by glutathione. J Agric Food Chem 58: 7949-7954.

15) Lucisano M, Cappa C, Fongaro L, Mariotti M. 2010. Methods for the characterization of breadcrumb, an important ingredient of stuffed pasta. J Cereal Sci 51: 381-387.

16) Yamaguchi T, Katsuda M, Oda Y, Terao J, Kanazawa K, Oshima S, Inakuma T, Ishiguro Y, Takamura H, Matoba T. 2003. Influence of Polyphenol and Ascorbate Oxidases during Cooking Process on the Radical-Scavenging Activity of Vegetables. Food Sci Technol Res 9(1): 79-83.

17) Singleton VL, Rossi JA. 1965. Colorimetry of total phenolics with phosphomolybdic-phosphotungstic acid reagents. Am J Enol Vitic 16: 144-158.

18) Shimada Y, Konishi F, Iijima K, Saito K, Kasai M, Hatae K. 2005. Effects of contact-dehydrating sheets on preference for fried food and deterioration of frying oil. $J$ Sci Food Agric 85: 305-309.

19) American Association of Cereal Chemists (AACC). 2000. Approved Methods of the American Association of Cereal Chemists. 10th ed. American Association of Cereal Chemists, St. Paul, Minnesota, USA.

20) Hamaker BR, Griffin VK. 1993. Effect of disulfide bondcontaining protein on rice starch gelatinization and pasting. Cereal Chem 70: 377-380.

21) Derycke V, Veraverbeke WS, Vandeputte GE, De Man W, Hoseney C, Delcour JA. 2005. Impact of proteins on pasting and cooking properties of nonparboiled and parboiled rice. Cereal Chem 82: 468-474.

22) Dyson DV. 1990. Breadings-What they are and How they are used. In: Batters and Breadings in Food Processing (Karel K and Loewe R, eds), p 143-152. American Association of Cereal Chemists, Inc., Minnesota.

23) Zweytick G, Berghofer E. 2009. Production of glutenfree beer. In: Gluten-Free Food Science and Technology (Gallagher E, ed), p 187. Wiley-Blackwell, UK. 